\title{
Uma Breve Reflexão Crítica sobre Psicologia Positiva e Resiliência.
}

\author{
Dell'Aglio, D.D., Koller, S. H., \& Yunes, M. A. M. (2006). Resiliência e psicologia positiva: \\ interfaces do risco à proteção. São Paulo, SP: Casa do psicólogo, 289p.
}

Falar sobre resiliência e psicologia positiva é, fundamentalmente, destacar o novo foco que estas concepções teóricas fornecem para o entendimento das trajetórias de vida. Estas abordagens rompem com o viés negativo e reducionista de teorias embasadas e focalizadas apenas em aspectos psicopatológicos e voltam-se para o que há de saudável e de positivo na vida e no desenvolvimento do ser humano. Dessa forma, dilui-se a noção em que o indivíduo se vê aprisionado a um ciclo sem saída.

A psicologia positiva busca o entendimento dos processos e fatores que proporcionam 0 desenvolvimento psicológico sadio. Além disso, nesta perspectiva interessa saber quais elementos implicam o fortalecimento e a construção de competências nos indivíduos, grupos e instituições (Seligman \& Csikszentmihalyi, 2000). A resiliência trata de fenômenos que fomentam estas concepções. Por isso, a importância de discuti-las paralelamente. Resiliência remete à possibilidade de adaptação positiva em contextos de adversidade e de riscos significativos e, neste sentido, contribui para a compreensão das forças humanas. Essa possibilidade produz efeitos importantes na vida dos indivíduos, uma vez que favorece as potencialidades, tornandoos mais fortes e produtivos (Paludo \& Koller, submetido).

Esta resenha tem como objetivo apresentar o livro Resiliência e psicologia positiva: Interfaces do risco à proteção, cuja leitura é importante para provocar a reflexão acerca destas concepções teóricas e discutir a aplicação das mesmas em pesquisas e intervenções. Os capítulos presentes no livro organizado pelas professoras e pesquisadoras Débora Dalbosco Dell'Aglio, Sílvia Helena Koller e Maria Angela Mattar Yunes trazem diversos estudos que problematizam questões conceituais, metodológicas e intervenções envolvendo resiliência e psicologia positiva.
A obra é dividida em duas partes. A primeira traz a conceituação e as interfaces da resiliência e da psicologia positiva nos três primeiros capítulos. A segunda parte traz um capítulo de considerações metodológicas no estudo da resiliência e, a seguir capítulos sobre pesquisas e intervenções envolvendo temáticas como violência, rede de apoio social e afetiva, entre outras.

O primeiro capítulo de Michele Poletto e de Sílvia Helena Koller, intitulado Resiliência: Um perspectiva conceitual e histórica, traz considerações sobre o conceito de resiliência, envolvendo suas principais características e sua evolução ao longo do tempo. Discute ainda a relação entre resiliência e outros conceitos a ela associados e relacionados ao desenvolvimento humano, tais como fatores de proteção, fatores de risco e vulnerabilidade. As autoras utilizam a teoria bioecológica do desenvolvimento de Urie Bronfenbrenner (1979/1996) como proposta teórica e metodológica que contribui para a compreensão do processo de resiliência e das interações das pessoas com seus contextos e trajetórias de vida.

A seguir, com o capítulo intitulado Psicologia positiva e resiliência: Foco no indivíduo e na família, Maria Angela Mattar Yunes apresenta o conceito de resiliência inserida como um dos focos principais em investigações da psicologia positiva. Tal perspectiva reforça a importância deste constructo para a compreensão de processos psicológicos que explicam a superação de adversidades, além de investigar padrões saudáveis de vida. $O$ capítulo estabelece um diálogo entre pesquisas quantitativas e qualitativas sobre resiliência. Ao focalizar as primeiras, são apresentados os aspectos individuais ou características que definem a resiliência como capacidade humana. As pesquisas qualitativas, ao estudarem a resiliência em famílias, trazem dados obtidos a partir de 
investigações com enfoque ecológico, sistêmico e de desenvolvimento. O capítulo ainda alerta os pesquisadores sobre os diferentes discursos e as controvérsias ideológicas conceituais que permeiam a aplicabilidade do termo resiliência.

Na seqüência, o capítulo de Simone Paludo e Silvia $\mathrm{H}$. Koller apresenta a psicologia positiva e suas origens. Dado o foco estudado pela psicologia positiva, os aspectos saudáveis do desenvolvimento humano, este capítulo se destaca ao fazer uma discussão entre as emoções vividas pelo ser humano e o fenômeno de resiliência. Além de retomar a importância do estudo das emoções positivas, discute a possibilidade destas funcionarem como fator de proteção em situações adversas, consideradas como risco. Neste sentido, resultados saudáveis e respostas adaptadas dos indivíduos deflagram o uso da capacidade de resiliência. As autoras ainda assinalam que estratégias de intervenções devem também estar atentas às emoções.

Com o propósito de discutir considerações relacionadas ao método no estudo da resiliência, Renata M. C. Libório, Bernardo M. de Castro e Ângela R. L. Coelho trazem o quarto capítulo intitulado Desafios metodológicos para a pesquisa em resiliência: Conceitos e reflexões críticas. Os autores apresentam uma análise de propostas metodológicas de pesquisas em resiliência e, ao mesmo tempo, fazem articulações com a discussão conceitual sobre os processos de resiliência. Discutem as primeiras pesquisas sobre resiliência com a conotação de invencibilidade dos indivíduos, passando pelo questionamento desta concepção e voltando-se para o valor das interações entre as pessoas mais próximas e significativas. A seguir, apresentam os processos de resiliência estudados também em famílias e nas interações dos indivíduos com o meio e instituições. Seguindo a análise dos autores, foram privilegiados, inicialmente, o estudo dos fatores de risco. No entanto, atualmente, diversos estudos têm investigado mecanismos e fatores de proteção. Sugerem também que os estudos sobre resiliência deveriam adotar o Modelo Ecológico de Bronfenbrenner, serem cuidadosos ao considerar o contexto social e buscar os sentidos que os participantes dão aos termos-chave usados na investigação. Apresentam estudos sobre resiliência desde propostas metodológicas quantitativas até as qualitativas (inserção ecológica, por exemplo) e questionam a mensuração de resiliência, destacando a necessidade de buscar o entendimento dos processos complexos e dinâmicos. Os autores ainda apontam algumas condições fundamentais que devem nortear pesquisas sobre esta temática, entre elas a inclusão de definições claras de resiliência, o reconhecimento multidimensional do conceito e o valor de investigações em diferentes pontos do desenvolvimento humano.

Os capítulos seguintes abordam intervenções e investigações embasadas no conceito de resiliência. O primeiro deles é intitulado Resiliência familiar: Baixa renda e monoparentalidade de Narjara M. Garcia e Maria Ângela M. Yunes e traz reflexões teóricas e metodológicas sobre o fenômeno de resiliência em famílias e suas inter-relações com a monoparentalidade e pobreza. Os processos de superação de adversidades, presentes na dinâmica da unidade familiar são entendidos como resiliência familiar. As autoras apresentam uma pesquisa com abordagem qualitativa com famílias chefiadas por mulheres pobres e fazem uma análise das histórias de vida das participantes e de suas famílias. O capítulo contribui para o entendimento de novos processos e possibilidades de resiliência familiar que transcendem configurações familiares e níveis socioeconômicos.

Violência e pobreza: Um estudo sobre vulnerabilidade e resiliência familiar é o título do sexto capítulo escrito por Clarissa De Antoni, Luciana Rodriguez Barone e Sílvia H. Koller. Nele, as autoras buscam a compreensão sobre como, em contextos familiares nos quais o abuso físico e a miserabilidade econômica estão presentes, se estabelecem as interações familiares que podem levar aos processos de resiliência e à vulnerabilidade. $O$ capítulo traz um estudo de caso de uma família pobre na qual a violência se apresenta como forma de manifestação da vulnerabilidade individual e familiar associada a outros severos e intensos eventos estressores. A análise do caso é baseada na Teoria Bioecológica do Desenvolvimento Humano (Bronfenbrenner, 1979/1996; 2004), buscando ainda identificar os indicadores de risco, 
fatores de proteção e os processos de resiliência familiar. A temática que permeia a história da família relatada no capítulo é, infelizmente, "comum" em milhares de famílias brasileiras que necessitam de apoio, intervenção e suporte de profissionais, instituições e de políticas públicas efetivas e eficazes.

$\mathrm{Na}$ seqüência, o capítulo de Luciana Cassol e Clarissa De Antoni intitulado Família e abrigo como rede de apoio social e afetiva apresenta um estudo de caso de uma adolescente, analisando suas interações em dois contextos distintos: na escola e no abrigo. Para a realização desta análise, as autoras utilizam como perspectivas teóricas a Teoria Bioecólogica do Desenvolvimento Humano (Bronfenbrenner, 1979/ 1996; 2004) e os conceitos de vulnerabilidade e resiliência. As autoras apresentam também considerações sobre o contexto da família e do abrigo no desenvolvimento de crianças e adolescentes, especialmente pela influência exercida por estes ambientes.

No capítulo intitulado Constituição de moradas nas ruas como processos de resiliência em adolescentes, Lene Lima Santos e Débora Dalbosco Dell'Aglio abordam a vivência de adolescentes em situação de rua. $O$ capítulo discute o conceito de resiliência vinculado à constituição da rua como uma morada possível, embora precária, para adolescentes que vivem nesta situação. As autoras problematizam a saída dos adolescentes de casa e a ida para a rua, pois, muitas vezes assim, estes jovens rompem com um padrão sociofamiliar imposto, no qual sofrem abusos e privações. Neste contexto eles demonstram também a habilidade dos adolescentes de reorganizar suas vidas de forma produtiva e por conta própria, e assim, criam novas formas de ajuste psicossocial. No entanto, esta ruptura os coloca frente a alguns riscos, embora os retire de outros e lhes ensina estratégias de sobrevivência. $O$ capítulo faz ainda uma análise de conceitos relacionados aos processos de resiliência, tais como coping, vulnerabilidade e competência e descreve o contexto ecológico da rua. Por fim, articula os processos de resiliência ao conceito de habitarmorar.

Luísa F. Habigzang e Sílvia H. Koller trazem o capítulo intitulado Terapia cognitivo-comportamental e promoção de resiliência para crianças e adolescentes vítimas de violência sexual intrafamiliar. A violência sexual contra a criança e o adolescente é o tema central e expressa a necessidade de intervenções efetivas para um problema que é considerado de saúde pública. Através dele, as autoras discutem a promoção de resiliência em crianças e adolescentes que foram vítimas de violência sexual intrafamiliar utilizando a terapia cognitivo-comportamental. Apresentam questões teóricas relacionadas à violência sexual intrafamiliar e à abordagem psicoterapêutica usada no tratamento de crianças vítimas deste abuso. Trazem ainda a apresentação de um programa de atendimento para crianças vítimas de abuso sexual em desenvolvimento.

Neuroplasticidade e resiliência em crianças e adolescentes vítimas de maus-tratos é o título do último capítulo e foi escrito por Jeane Lessinger Borges, Christian Haag Kristensen e Débora Dalbosco Dell'Aglio. Este capítulo explora variáveis relacionadas à plasticidade do sistema nervoso (neuroplasticidade) envolvidas nos processos de resiliência. $\mathrm{Na}$ literatura, o uso deste aspecto é recente quando direcionado para o estudo da violência contra crianças e adolescentes (Glaser, 2000). Sob este referencial, os autores discutem maus-tratos na infância e na adolescência e descrevem as principais alterações neurobiológicas associadas a esta condição. Trazem, ainda, o conceito de plasticidade como uma característica individual participante dos processos de resiliência e, assim, ao considerarem a resposta neurobiológica individual como um mecanismo de adaptação ao ambiente social e familiar, ampliam a análise, incluindo os processos contextuais que promovem resiliência.

O livro Resiliência e psicologia positiva: Interfaces do risco à proteção instiga os leitores a refletirem acerca de novas perspectivas do desenvolvimento humano. Esta visão é guiada pela Abordagem Bioecológica do Desenvolvimento Humano (Bronfenbrenner, 1979/ 1996; 2004) e pela Psicologia Positiva que permitem uma nova concepção de saúde e um olhar cauteloso sobre as situações de riscos vivenciadas pelas pessoas. Os textos são marcados por inúmeras situações que evidenciam a superação de riscos e a ruptura de um 
ciclo no qual o indivíduo se vê sem possibilidades e perspectivas.

A leitura de um capítulo após o outro pode revelar algumas repetições que poderiam ser desnecessárias, especialmente porque abordam o mesmo assunto. No entanto, permitem que os leitores possam transitar de um texto a outro, conforme seu interesse e sem necessariamente respeitar a seqüência proposta pelas organizadoras. Ao longo do livro as idéias assumem um novo sabor do contexto ecológico no qual se desenvolvem crianças, jovens e adultos. Outro aspecto saliente é o foco em conceitualizações e não em conceitos. A conceitualização traduz a dinamicidade dos temas. Resiliência e Psicologia Positiva são trazidas em abordagens processuais e dinâmicas, por sua novidade e construção teórica recente nesta área da ciência. O livro certamente contribui para o embasamento teórico de estudos, e para planejamento de intervenções consistentes e baseadas na saúde. No entanto, a recenticidade destes modelos desvela-se pela ausência de um capítulo que apresente uma proposição metodológica consistente. Este dado revela que estas temáticas carecem de investigações, instrumentos de avaliação, métodos e técnicas para avançar o conhecimento.

Esta resenha é um convite a conhecer o livro, pois instrumentaliza estudantes, profissionais e pesquisadores de Psicologia e áreas afins para suas práticas. Oferece ainda reflexões quanto à importância e influência dos contextos na vida do ser humano, bem como da necessidade de integrar fatores de risco e de proteção para a melhor compreensão do desenvolvimento humano. Apenas através desta integração serão possíveis novos conhecimentos e subsídios efetivos para políticas públicas eficazes e para a melhoria da qualidade de vida.

Michele Poletto Centro de Estudos psicológicos sobre meninos e meninas de Rua (CEP-RUA/UFRGS) 